\title{
Construção de jogos não digitais por alunos - um relato de experiência
}

Thiago Reis da Silva - IFMA/Campus São João dos Patos - thiago.reis@ifma.edu.br Leilson Dutra da Silva - IFMA/Campus São João dos Patos - lealsjp@ gmail.com Luiz Leonardo Duarte Garcia - IFMA/Campus São João dos Patos luiz.garcia@ifma.edu.br

Renato Darcio Noleto Silva - IFMA/Campus São João dos Patos renato.silva@ifma.edu.br

Resumo. Este artigo apresenta os resultados de uma experiencia de desenvolvimento de jogos não digitais em uma disciplina de Informática Educacional com 120 discentes dos cursos de Licenciatura Plena em Matemática e Física. Os participantes puderam refletir sobre o impacto da utilização desse método criativo no processo de ensino $e$ aprendizagem, exercitando na prática a definição de um conceito de jogo como solução a problemas relacionados com as disciplinas citadas. Os alunos demonstraram compreender os conceitos apresentados, além de manterem-se engajados na realização das atividades. Os resultados favorecem a apresentação dos conteúdos e se manifestam como uma possibilidade relevante para auxiliar o processo de ensino e aprendizagem dos conteúdos abordados.

Palavra-chave: jogos não digitais, relato de experiências, matemática, física.

\section{Construction of non digital games by students - an experience report}

Abstract. This article presents the results of a non digital game development experience in an Educational Informatics discipline with 120 students of the Full Degree courses in Mathematics and Physics. The participants were able to reflect on the impact of using this creative method in the teaching and learning process, exercising in practice the definition of a game concept as a solution to problems related to the aforementioned disciplines. The students demonstrated to understand the concepts presented, in addition to remaining engaged in carrying out the activities. The results favor the presentation of the contents and manifest themselves as a relevant possibility to assist the process of teaching and learning the contents covered.

Keywords: non-digital games, experience reporting, mathematics, physics.

\section{Introdução}

Com o advento da Tecnologia de Informação e Comunicação (TIC), os docentes têm buscado meios de acompanhar e aplicar os diversos recursos tecnológicos ou metodológicos dentro da sala de aula, pois é notório que os alunos, em geral, são motivados e se sentem engajados quando imersos em ambientes inovadores e novas metodologias de ensino.

Diante deste cenário, mesmo com a inserção das TICs, propagadas muitas vezes como solução para os problemas no processo ensino e aprendizagem (ARAÚJO, SILVA e ARANHA, 2016) as salas de aula, em sua maioria ainda são as mesmas do século passado. Mas, a tecnologia sozinha não soluciona problemas sem a inteligência e o manuseio hábil daqueles que estão diante dos alunos todos os dias, os professores. Neste ponto, surge a necessidade de preparar os professores para utilização das novas metodologias que podem ou não recorrer a recursos tecnológicos. 
Sendo assim, a utilização de jogos com fins educativos é considerada tendência em ambientes acadêmicos. A tendência para o uso de jogos como agente motivador da aprendizagem em sala de aula, aliada às vantagens que o uso de jogos pode proporcionar no processo de ensino e aprendizagem, estimulam a produção de jogos. Afinal, entretenimento e diversão eram elementos inadmissíveis nas salas de aulas no passado.

Existem estudos sobre o uso de jogos como motivador no processo de ensino e aprendizagem e para o ensino de várias disciplinas, entre elas, Matemática e Física. No entanto, embora a maioria dos jogos educacionais existentes para o ensino sejam digitais, atualmente, há também uma tendência na adoção de jogos não digitais.

McGonigal (2012), relata que a humanidade passa cerca de três bilhões de horas semanais jogando. Tal indicador qualifica e reforça o papel relevante que os jogos desempenham na sociedade, seja na perspectiva do entretenimento ou no seu potencial educacional.

No ensino de matemática, os Parâmetros Curriculares Nacionais (PCN), orientam professores a utilizar os jogos como um dos "caminhos para fazer matemática na sala de aula". Para os PCN

Os jogos podem contribuir para um trabalho de formação de atitudes desafios, lançar-se à busca de soluções, desenvolvimento da crítica, da intuição, da criação de estratégias e da possibilidade de alterá-las quando o resultado não é satisfatório - necessárias para aprendizagem da Matemática (BRASIL, 1998, p. 47).

Nesta perspectiva, apresentamos neste artigo um relato de experiência de construção de jogos não digitais com discentes dos cursos de Licenciatura Plena em Matemática e Física do Instituto Federal do Maranhão (IFMA) - Campus São João dos Patos, na disciplina de Informática Educacional, que tiveram como objetivo o desenvolvimento de jogos não digitais para o ensino de Matemática ou Física. A disciplina teve carga horária de 30 horas e foi ministrada nos períodos de 2017.1, 2018.2, 2019.1 e 2019.2 e participaram 120 alunos.

Sendo assim, este trabalho está organizado da seguinte forma: na Seção 2 aborda sobre jogos não digitais e formação de professores, na Seção 3 apresenta a metodologia do estudo, na Seção 4 apresenta os resultados, na Seção 5 detalha algumas discussões e, por fim, na Seção 6 são abordadas as considerações finais.

\section{Jogos não digitais e formação de professores}

Dentre as várias categorias de jogos, existem aquelas que não são desenvolvidas a partir das ferramentas tecnológicas. Alguns desses jogos não digitais são conhecidos como boardgames e cardgames. Os jogos não digitais se diferenciam dos jogos digitais pelo fato de estarem dispostos no papel ou tabuleiro feito de papelão.

Atualmente, a maioria dos jogos educacionais existentes para o ensino de Matemática e Física são digitais, mas, há também uma tendência na adoção de jogos não digitais, na sua maioria, jogos de tabuleiro e cartas para o ensino de diversas áreas. Esta tendência pode ser corroborada pelo fato de que a maioria dos jogos educacionais serem desenvolvidas pelos próprios professores, com recursos e infraestrutura limitada. E Segundo Petri et. al., (2017) o desenvolvimento dos jogos digitais requer um esforço considerável, muitas vezes esses jogos não alcançam todo o seu potencial. Por outro lado, os jogos não digitais tendem a ter um menor esforço no seu desenvolvimento, por não requerer o uso de uma ferramenta tecnológica para a sua construção, utilizando 
componentes como papel e lápis um professor da área de Matemática ou Física pode desenvolver seu próprio jogo.

Nesta perspectiva, estudos têm demonstrado que a utilização das novas metodologias, entre elas os jogos, como ferramenta para auxiliar os professores, traz uma contribuição para a prática escolar em vários níveis de ensino (PROCÓPIO, 2011). Essa utilização apresenta possibilidades que poderão ser realizadas como auxílio nas atividades pedagógicas. Porém, o debate sobre a formação de professores, bem como as possibilidades e desafios dessa formação é outro ponto que vem sendo pesquisado. Bittar (2011) debate a formação de professores de forma que esses passem a integrar novos recursos, sejam eles digitais ou não em suas aulas e não apenas inseri-las como um recurso ilustrativo e motivador. Neste aspecto, é necessária uma formação continuada para atualizar esses profissionais.

A formação de professores por meio das novas metodologias - jogos digitais e não digitais, ensino híbrido, gamificação, aula invertida e outros - visa o desenvolvimento profissional e proporciona a qualificação acadêmica (PROCÓPIO, 2011). Projetos de formação de professores realizados com apoio de jogos não digitais vêm auxiliar na elaboração de materiais de apoio à formação desses futuros docentes. Sendo assim, considerando os aspectos citados foi elaborada uma proposta de formação de futuros professores para o desenvolvimento de jogos não digitais que trabalhasse conteúdos de Matemática e/ou Física.

\section{Metodologia}

Este trabalho trata-se de uma pesquisa aplicada, baseado no estudo de Silva (2017). Sendo assim, apresentaremos uma experiência acerca do desenvolvimento de jogos não digitais, no contexto de uma disciplina de Informática Educacional com alunos dos cursos de Licenciatura Plena em Física e Matemática.

$\mathrm{Na}$ construção dos jogos foram utilizados materiais recicláveis, como tampa de garrafas, papelão, garrafas pet, entre outros. As atividades propostas com $o$ desenvolvimento e aplicação entre os alunos foram desenvolvidas durante a disciplina, entre os anos de 2017 a 2019, a fim de levantar um conjunto de jogos que mostrassem a diversidade de ideias através dos conceitos das disciplinas citadas. Em cada apresentação os alunos tinham entre 15 a 40 minutos para apresentar o jogo e os demais jogarem. $\mathrm{O}$ método utilizado para a concepção dos jogos e apresentação dos resultados adotou as seguintes fases (SILVA, 2017):

- Levantamento bibliográfico: realizou-se pelas equipes um levantamento, contemplando os processos de desenvolvimento de jogos e a sua aplicação prática no ambiente escolar;

- Planejamento e preparação dos jogos: preparação dos recursos e conteúdo a serem utilizados no desenvolvimento dos jogos;

- Orientações para a definição de um conceito de jogo utilizando os processos do Game Design: foi apresentado um passo a passo do processo criativo do conceito de jogo dentro do Game Design. O passo a passo aplicado foi: (i) formulação do problema; (ii) compreensão do problema; (iii) sessão de Brainstorming para definição de soluções; (iv) descrição da melhor solução; (v) refino da melhor solução; (vi) elaboração do Game Design Document (GDD) através do Página-Única;

- Apresentação dos jogos: a partir das orientações das fases anteriores, foi solicitado aos participantes que criassem um jogo não digital a partir da compreensão de um problema e apresentassem a sua solução em sala de aula. 


\section{Resultados}

O projeto possibilitou aos participantes conhecerem noções básicas sobre jogos e o seu processo de criação, além de refletirem sobre a viabilidade do uso dos jogos não digitais como ferramenta para auxiliar o processo de ensino e aprendizagem. Sendo assim, para desenvolverem os projetos, os alunos tinham que atender os seguintes requisitos:

- Criar um jogo de tabuleiro, cartas, ou outro, a partir dos conceitos e práticas do ensino de Física ou Matemática, para qual nível de escolaridade (ex., ensino médio ou superior), que ensine aos que jogam os conteúdos da disciplina; e

- Utilizar para a confecção dos artefatos do jogo preferencialmente material reciclado.

\subsection{Perfil dos alunos}

O estudo foi realizado com a participação de 120 discentes conforme detalhado na Tabela 1. Desses 81 são alunos do curso de Licenciatura Plena em Matemática e 39 de Física. Em relação ao sexo: $60 \%$ do sexo feminino e $40 \%$ são do sexo masculino. Os alunos tinham entre 17 a 35 anos de idade. Para realização das atividades propostas foram divididos grupos de no mínimo quatro e no máximo seis alunos.

Tabela 1: Perfil dos Alunos.

\begin{tabular}{|c|c|c|c|c|}
\hline Ano & Alunos & Grupos & Curso & Sexo \\
\hline 2017.1 & 26 & 4 & Matemática & $69 \%$ M e $31 \% \mathrm{H}$ \\
\hline 2018.2 & 27 & 4 & Matemática & $59 \% \mathrm{M} \mathrm{e} 41 \% \mathrm{H}$ \\
\hline 2019.1 & 28 & 4 & Matemática & $57 \% \mathrm{M} \mathrm{e} 43 \% \mathrm{H}$ \\
\hline 2019.2 & 39 & 6 & Física & $56 \% \mathrm{M} \mathrm{e} 44 \% \mathrm{H}$ \\
\hline
\end{tabular}

\subsection{Template dos jogos}

Nesta etapa foi proposto aos estudantes a elaboração de um jogo não digital em grupo, onde utilizando conhecimentos e criatividade, criem jogos com os objetivos definidos por eles. Os grupos tiveram liberdade de escolher o conteúdo, sendo dado um exemplo de uma proposta de um jogo (template) e em seguida foi solicitado que o grupo crie seu próprio jogo, atendendo os seguintes requisitos estabelecidos na Seção 4.

Nos jogos foi solicitado aos grupos que detalhassem as regras com instruções de uso e funcionamento. Nesse documento foram também solicitadas outras mecânicas de jogos, como níveis, pontuação, entre outros, caso existisse.

Para elaboração do manual do jogo, foi apresentado algumas regras para projetar o mesmo, mostrando que é importante inicialmente debater e anotar as ideias (brainstorming), definir o conteúdo do jogo, a faixa etária dos jogadores, o número mínimo e máximo de jogadores e o tempo médio que os jogadores levarão para concluir uma jogada.

\subsection{Jogos não digitais desenvolvidos pelos alunos de Matemática}

As atividades com os discentes do curso de Matemática ocorreram conforme apresentando na Tabela 1. Para o desenvolvimento do jogo um problema foi definido para que os alunos apresentassem uma solução, que consistia em: "Criar um jogo não digital que trabalhe habilidades e/ou conteúdos em componentes curriculares do ensino de Matemática em quaisquer níveis de ensino?". A seguir são apresentados alguns jogos propostos pelos discentes. Ao total foram criados 12 jogos pelos alunos de Matemática.

\section{Matemática Divertida}

O "Matemática Divertida" - Figura 1 (a) - é um jogo de tabuleiro nos moldes do banco imobiliário. $\mathrm{Na}$ intenção de uma melhor interação dos alunos com a Matemática, V. $18 \mathrm{~N}^{\mathrm{o}} 1$, julho, 2020 RENOTE DOI: 
especialmente, com os conteúdos de divisão e multiplicação o jogo foi criado. Trata-se de um jogo educativo para todos os públicos estudantis, mas especialmente para os alunos do ensino fundamental maior, que estão em fase de aperfeiçoamento das operações de multiplicação e divisão, auxiliando os alunos a interpretarem melhor as operações matemáticas. O jogo foi criado com o seguinte objetivo: facilitar a interação dos alunos com a tabuada; melhorar o envolvimento do aluno na tarefa proposta pelo jogo; melhorar suas habilidades com a interpretação de questões e melhores formas de resolvê-las, ser acessível e de fácil uso.

O jogo se inicia da seguinte maneira: primeiramente são escolhidos dois ou quatro participantes e depois eles tiram par ou ímpar para decidir quem vai iniciar. No tabuleiro em cada casa possui uma questão para que o aluno resolva, caso não consiga resolver o aluno/jogador voltará para a casa anterior. Cada questão tem um tempo limite de dois minutos para responder. Ganha o jogador que conseguir chegar primeiro ao fim do tabuleiro e responder todas as questões propostas. Na Figura 1(b) foi apresentado os alunos jogando.

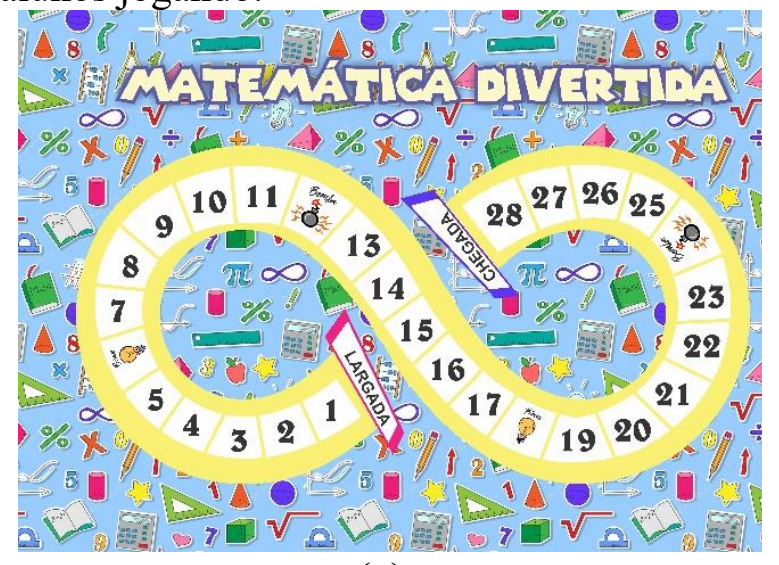

(a)

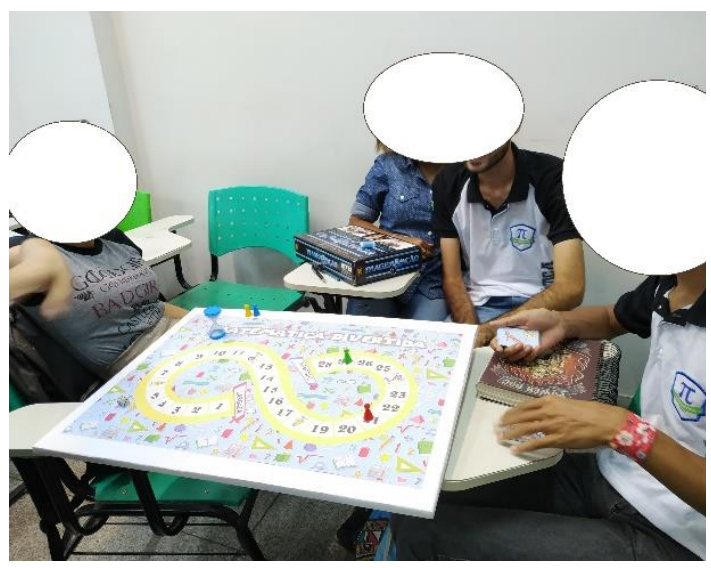

(b)

Figura 1: (a) Matemática Divertida e (b) Exibição do Jogo.

Para o jogo Matemática Divertida, o modo como os alunos analisaram o problema apresentado e o modo criativo, como pensaram nas soluções demonstrou que a etapa de definição de conceito foi bem executada. Durante as atividades, percebeu-se uma descontração e muita liberdade para criar. $O$ envolvimento de todos também foi observado, mesmo daqueles mais tímidos.

\section{Sequência Lógica}

O "sequência lógica" é um jogo de tabuleiro voltado para o assunto de Progressão Aritmética (PA) e Geométrica (PG), com sequências de números, onde há dois espaços vazios, que o jogador terá que completar esses espaços com a sequência de números (progressão), ou seja "P.A" ou "P.G" e o outro espaço vazio com a razão dessa sequência de números (progressão), conforme ilustra a Figura 2.

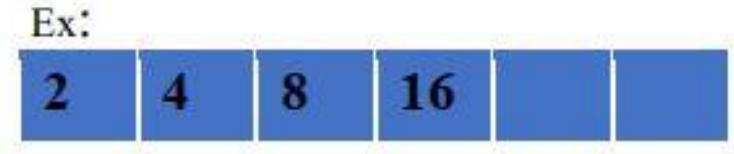

Resposta do jogador:

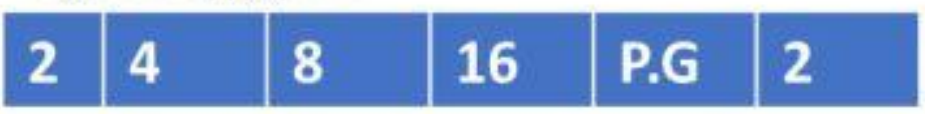

Figura 2: Exemplo de um problema do jogo.

V. $18 \mathrm{~N}^{\mathrm{o}}$ 1, julho, 2020

DOI: 
O jogo foi em um tabuleiro que possui dez quadrados na vertical e seis na horizontal, onde os quatro primeiros quadrados na horizontal estão as sequências de números (progressão). Já no quinto quadrado da horizontal o jogador vai completar o espaço vazio com uma P.A ou P.G, o sexto quadrado na horizontal o jogador vai completar com a razão desta sequência (progressão). As regras podem ser resumidas como: uma dupla por partida; cada jogador terá cinco progressões à sua disposição, sendo elas duas fáceis, duas médias e uma de difícil complexidade; os dois oponentes terão entre cinco e oito minutos para responder às questões propostas, ficando o tempo variável em medida do grau de complexidade para cada aluno. A Figura 3 ilustra um momento da aplicação do jogo com os alunos.

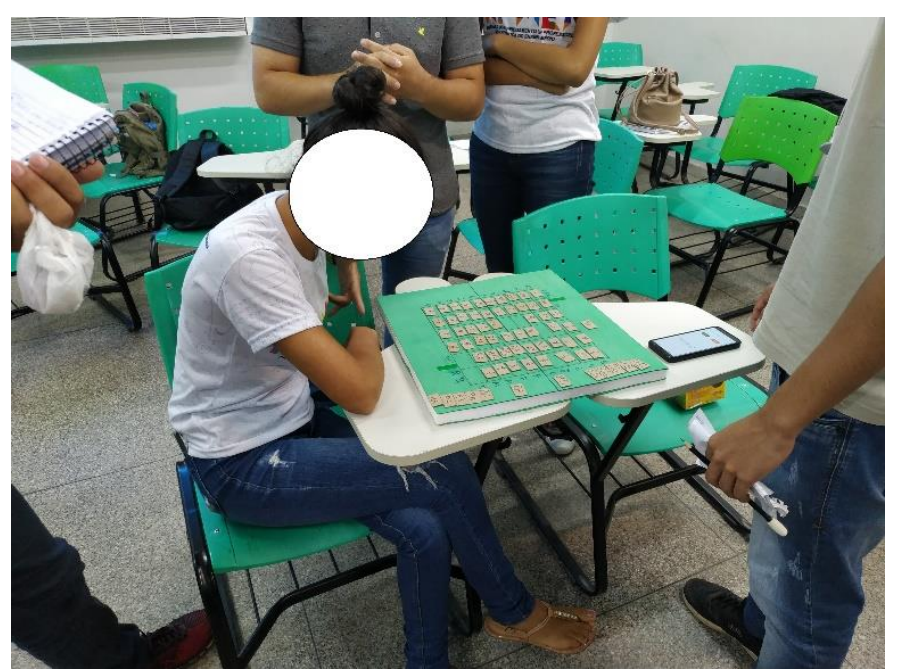

Figura 3: Aplicação do jogo Sequência Lógica.

O jogo tem como objetivo incentivar os alunos do ensino médio a raciocinar mais rápido, tanto para identificar a razão das progressões, como para verificar se é uma P.A ou P.G. Assim, o aluno estará mais motivado pelo assunto, fazendo despertar o interesse por Matemática. O público alvo do jogo são os alunos do ensino médio.

\section{BingoMática}

O "BingoMática" é uma adaptação do tradicional bingo. É um jogo voltado para aplicação da tabuada e do conhecimento básico das figuras geométricas, haja vista, a necessidade que os estudantes têm de aprenderem a tabuada e a Geometria Básica nos primeiros anos do ensino fundamental.

O jogo é praticado por até cinco jogadores, onde cada jogador aguardará o sorteio de uma "pedra" onde está detalhado um problema da tabuada ou o nome de uma figura geométrica. Diante disso, o mesmo deve tentar resolver o problema e procurar o resultado em uma cartela, por exemplo, se a pedra sorteada é $2 \times 9$ e o jogador souber a resposta, ele não poderá falar alto ou sussurrar ao colega (pois assim ele estará facilitando para o adversário), ele verificar em sua cartela se tem o número 18, caso positivo, ele deverá marcar com uma "pedra" aquele número. Os jogadores farão isso até que um deles preencha uma cartela toda.

Este jogo tem por objetivo incentivar e tornar divertida a aprendizagem de tabuada e das figuras geométricas, onde os jogadores/alunos irão interagir, se divertir e se sentir estimulados pela mecânica do jogo, gerando conhecimentos pela tabuada e figuras geométricas. O público não se restringe apenas aos alunos do Ensino Fundamental I, pelo contrário, se expande a outras faixas etárias. No entanto, o jogo tem por objetivo 
aprimorar e incentivar o conhecimento matemático (tabuadas e figuras geométricas) de crianças de faixas etárias de oito a 12 anos ( $3^{\circ}$ ao $7^{\circ}$ ano).

\subsection{Jogos não digitais desenvolvidos pelos alunos de Física}

As atividades com os discentes do curso de Física ocorreram no período 2019.2. Para o desenvolvimento do jogo um problema foi elaborado, que consistia em: "Criar um jogo não digital que trabalhe habilidades e/ou conteúdos em componentes curriculares do ensino de Física em quaisquer níveis de ensino?". A seguir são apresentados alguns dos jogos propostos pelos discentes. Ao total foram criados seis jogos pelos alunos de física.

\section{Basquete de Papelão}

O jogo proposto utilizou a ideia do Angry Boards para o desenvolvimento. O propósito deste é ensinar os conceitos de velocidade, lançamento oblíquo e lançamento de projéteis. O enredo é desafiador para os jogadores: a ideia é inclinar o objeto para obter direção e sentindo a cesta - ver Figura 4 (a), onde o jogador tem que ponderar a velocidade com que vai lançar a bola. Cada jogador tem direito a três lances e se o participante conseguir acertar dois lances em diferentes cestas do seu adversário é considerado vencedor.

Primeiramente, os alunos tiveram a possibilidade de praticar o jogo em duplas e em seguida, debateram expondo suas dúvidas e dizendo suas estratégias para avançar no jogo. Após algumas tentativas de acertar a cesta, os alunos se sentiram instigados a tentar descobrir a velocidade certa para que o lançamento da bola caia na cesta, como ilustra a Figura 4 (b).

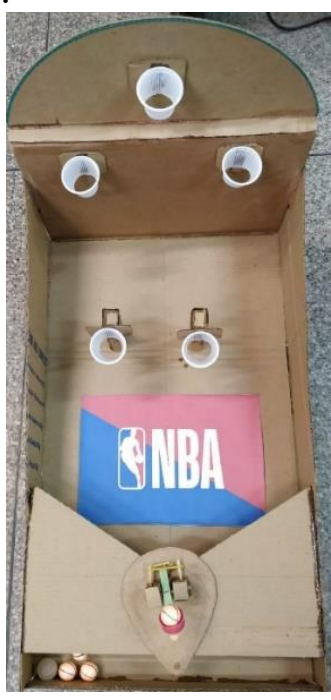

(a)

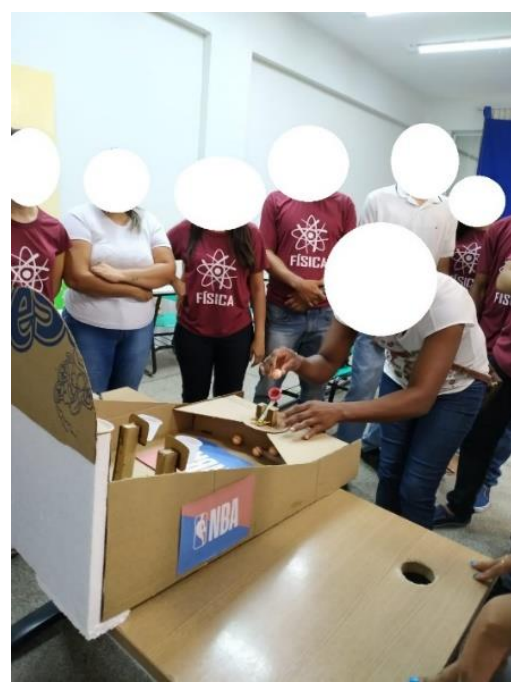

(b)

Figura 4: (a) Basquete de Papelão e (b) Aplicação com os alunos.

O público-alvo do jogo são os alunos do ensino médio e corrobora com o conteúdo de Lançamento Oblíquo (ou parabólico) que é geralmente discutido no primeiro ano do ensino médio dentro do estudo de movimentos, ou seja, um subtema da Mecânica. Sobre o conhecimento de movimentos os PCN abordam que:

\footnotetext{
O estudo dos movimentos inclui também acompanhar as conquistas do ser humano para locomover-se, desenvolvendo tecnologias que permitam seu deslocamento de forma cada vez mais rápida de um lugar a outro do planeta, e até mesmo fora dele e, para isso, concebendo continuamente materiais, projetos de veículos e potências de seus motores. Também são desse âmbito a compreensão da evolução tecnológica relacionada às máquinas mecânicas e suas transformações ao longo dos tempos (BRASIL, 2002).
} 
Agrupando tais características com os objetivos do estudo, a utilização do jogo "Basquete de Papelão" para o estudo de velocidade, lançamento oblíquo e lançamento de projéteis se torna uma atividade de potencial para a compreensão de um conteúdo importante no aprendizado dos alunos.

\section{Sorte de Iniciante}

O "Sorte de Iniciante" é um jogo de tabuleiro que foi pensado tomando como referência o jogo Banco Imobiliário, pela sua popularidade e fácil reconhecimento entre os jogadores. As ações do jogo proposto são mediadas por meio de perguntas e respostas, como pode ser observado na Figura 5 (a) e (b), sendo que cada pergunta ou resposta específica é dado um comando, como: avançar, ficar onde estar ou voltar de acordo com as respostas as questões.

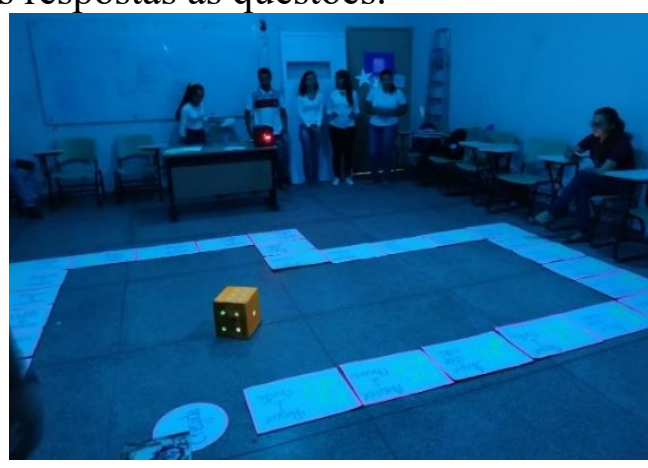

(a)

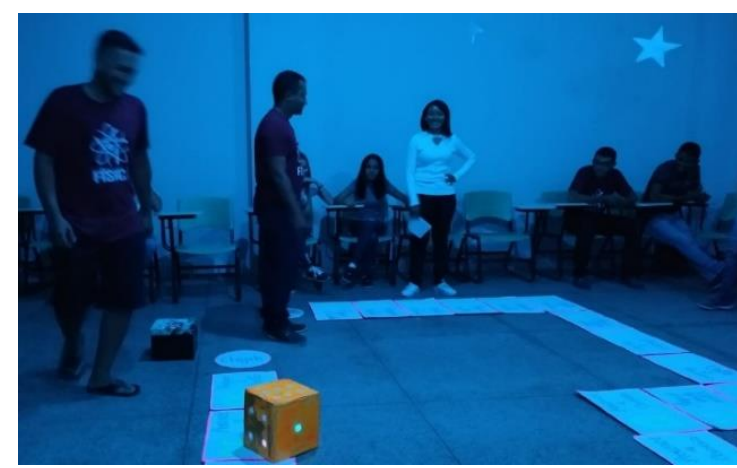

(b)

Figura 5: (a) Tabuleiro do Jogo e (b) Aplicação com os alunos.

O jogo proposto não possui fases, porém, o jogador terá que usar habilidades e conhecimentos da área para vencer. $O$ público alvo são os alunos do curso superior de Física e pode ser utilizado também no ensino médio.

As regras definidas basearam-se em jogos comuns de perguntas e respostas:

- Os dois jogadores arremessarão um dado e o que obter o maior número começará;

- Os dois jogadores jogarão novamente o dado e de acordo com o número obtido será o número de casa que terá que avançar;

- Em cada casa do tabuleiro haverá uma pergunta voltado para o conhecimento gerais do curso de Licenciatura Plena em Física;

- Caso o jogador não acerte a pergunta, ele terá uma consequência. Ele retirará a carta consequência de um baú e nela está descrita a consequência que terá de fazer, podendo ser: resolver uma questão no quadro, uma conta simples de tabuada, entre outras. Caso não cumpra a consequência ele volta para o início do jogo;

- O jogador que chegar primeiro ao final do tabuleiro é considerado o vitorioso.

A utilização de jogos em sala de aula tem-se mostrado uma maneira eficiente de proporcionar cenários desafiadores onde o aluno passa a lidar com a consequência de suas ações e também ser recompensado por elas (BERTONCELLI JUNIOR, AIKES JUNIOR e LOPES, 2018). Assim, o propósito deste jogo alinha-se à prática pedagógica e proporciona um ambiente lúdico de ensino e aprendizagem.

\section{Discussões}

Antes de iniciar a discussão dos resultados é importante ressaltar que não havia intenção alguma de generalização das informações obtidas. Desta forma, a avaliação foi direcionada especialmente à percepção dos alunos acerca dos jogos desenvolvidos, no intuito de relacionar essas percepções com os princípios de desenvolvimento adotados ao 
longo do processo de Game Design e com a perspectiva de aprendizagem. Outro aspecto que se deve enfatizar é que a proposta deste trabalho não era avaliar o desempenho e sim verificar se o protótipo de jogo desenvolvido tem potencial de atuar como ferramenta de aprendizagem em Matemática e Física.

A proposta de criação de jogos não digitais envolveu os alunos e estes, por conseguinte, escolheram o tema e desenvolveram colaborativamente seus jogos com desafios e problemas relacionados com a Matemática e Física de todos os níveis de ensino, envolvendo qualquer conteúdo das disciplinas citadas.

É importante ressaltar que a motivação e o engajamento na aprendizagem é uma tarefa complexa. Contudo, pode-se utilizar de mecanismos que permitam promover ou auxiliar para que os alunos mantenham ou recuperem o interesse no aprendizado (SYLVESTER, 2013). Portanto, o desenvolvimento desses jogos com ferramentas para auxiliar o processo de ensino e aprendizagem torna-se um exímio mecanismo nessa tarefa, por transformar o ambiente de aula propício a oportunizar entusiasmo, diversão, protagonismo, cooperação e inovação.

Os objetivos do trabalho desenvolvido foram atingidos. Ao final do trabalho esperava-se que o aluno fosse capaz de: produzir jogos de Matemática ou Física exercendo a autoria; criar roteiros e estratégias para produção de jogos; e desenvolver habilidades de argumentação, observação, trabalho em equipe, colaboração e espírito crítico.

Os jogos educacionais possuem aspectos que garantem a ludicidade e a interação do jogador com o jogo e os jogos desenvolvidos pelos alunos atingiram esse propósito. Novak (2010) afirma que os jogos são compostos por cinco elementos, divididos em: narrativa, personagens, jogabilidade, níveis e interfaces. E os jogos aqui propostos trabalharam três elementos: narrativa, jogabilidade e niveis. A narrativa compõe os elementos relacionados com a história do jogo, que pode contribuir para o envolvimento do jogador com os temas propostos e servir como motivação para os desafios. A jogabilidade abordar as tarefas, desafios, mecanismos que são controlados e interpretados pelo jogador durante o jogo e os níveis estão relacionados com os objetos ou personagens presentes em cada situação, o grau de dificuldade de alguma tarefa, tudo relacionado com a narrativa.

Sendo assim, adicionar o lúdico ao ensino não é uma prática recente. Várias pesquisas propõem o ensino baseado em ludicidade, no sentido de que podemos incluir brincadeiras no processo de ensino e o desenvolvimento de jogos não digitais vem a calhar o lúdico no processo de ensino e aprendizagem.

\section{Considerações Finais}

Atualmente, é fácil perceber o interesse de todos por jogos. Por isso, é necessário considerar fazer uso de novas propostas pedagógicas para o ensino e aprendizagem, utilizando meios, que além de fácil acesso, são interativos, despertam a curiosidade e interesse dos estudantes pelas atividades que serão propostas, já que se tem como recurso um material que é de uso comum entre todos.

Logo se faz necessário que os professores busquem adaptar-se à essa realidade, pois os alunos, em geral, sentem-se mais motivados a participar do processo de ensino e aprendizagem por intermédio das novas tecnologias e metodologias. Sendo assim, este estudo apresento uma experiência de sensibilização e formação de futuros professores, para a utilização de processos de criação de jogos, como apoio no processo ensino e aprendizagem.

V. $18 \mathrm{~N}^{\circ} 1$, julho, 2020 RENOTE

DOI: 
Foram propostos momentos nos quais os alunos puderam aprender sobre os fundamentos do desenvolvimento de jogos, além de praticar a definição do conceito de jogo utilizando os processos do Game Design e refletir sobre os ganhos e dificuldades para a implantação desses processos nas escolas. Esta experiência pode ser utilizada não só para iniciar o trabalho de preparação de novos professores, como também, para servir de formação continuada para outros professores.

Sobre os ganhos, os alunos perceberam que a utilização dos processos de criação de jogos não digitais pode estimular a organização e colaboração em grupos para o desenvolvimento de projetos em diversas áreas. Esta pesquisa, apesar de refletir um estudo pontual, evidencia a possibilidade de se trabalhar com o desenvolvimento de jogos não digitais pelos discentes, especialmente no processo de formação continuada. Em trabalhos futuros, pretende-se apoiar os discentes para aplicação dos jogos desenvolvidos nas escolas da região.

\section{Referências}

Araújo, G. G.; Silva, T. R.; Aranha, E. H. S. A Construção de Jogos Digitais na Escola: um Relato de Experiência na Formação de Professores. In: Anais do Workshop de Informática na Escola - WIE, p.161-170, Uberlândia - MG, 2016.

Bertoncelli Junior, C. A.; Aikes Junior, J.; Lopes, R. P. Desenvolvimento e Aplicação de um Jogo na Disciplina de Gerenciamento de Sistemas e Redes. In: Simpósio Brasileiro de Jogos e Entretenimento Digital - SBGAMES, 2018.

Brasil. Secretaria de Educação Fundamental. Parâmetros Curriculares Nacionais: Física / Secretaria de Educação Fundamental. Brasília: MEC / SEF, 1998.

Brasil. Secretaria de Educação Fundamental. Parâmetros Curriculares Nacionais: Matemática / Secretaria de Educação Fundamental. Brasília: MEC / SEF, 1998.

Brasil. Secretaria de Educação Média e Tecnológica. Orientações Educacionais Complementares aos Parâmetros Curriculares Nacionais - Ciências da Natureza, Matemática e suas tecnologias. Brasília: MEC, 2002.

Bittar, M. A abordagem instrumental para o estudo da integração da tecnologia na prática pedagógica do professor de matemática. In: Educar em Revista: Editora UFPR, Curitiba, Brasil, n.1, p. 157-171, 2011.

Mcgonigal, J. A realidade em jogo: porque os games nos tornam melhores e como eles podem mudar o mundo. Rio de Janeiro: Bestseller. 2012.

Novak, J. Desenvolvimento de games. Cengage Learning, São Paulo - SP, Brasil, 2010

Petri, G.; Gresse von Wangenheim, C.; Borgatto, A. F. Quality of Games for Teaching Software Engineering: An Analysis of Empirical Evidences of Digital and Non-digital Games. Proc. of the 39th Int. Conf. on Software Engineering: Software Engineering Education and Training Track, (pp. 150-159). Buenos Aires, Argentina, 2017.

Procópio, E. R. Formação de professores e tecnologias: implicações da educação a distância na prática docente. (Dissertação) Universidade Federal de Juiz de Fora, 139p, 2011.

Silva, T. R. Um Relato de Experiência da Aplicação de Gamificação e Game Design com Professores. Anais do Workshop de Informática na Escola. Vol. 23. No. 1. 2017.

Sylvester, T. Designing games: A guide to engineering experiences. O'Reilly Media, Inc., 2013. 